\title{
What every policy maker needs to know about cognitive benefits of bilingualism
}

\author{
Dina Mehmedbegovic
}

\section{Introduction}

The Manifesto for Languages produced by the APPG (All-Party Parliamentary Group on Modern Languages 2014) argued that the UK needs to have a strategy for 'national recovery in language learning'. The Manifesto calls for a set of important commitments to be made by the political parties in the next general election, which would form a Framework for National Recovery in Language Learning. In this document it is suggested that $£ 48$ billion could be added to the UK economy if 'national competence in languages is revived'. The Manifesto exposes the severity of language learning decline at different levels.

My intention for this chapter is to present the case for an approach that can be applied at individual, institutional and national level, as a national strategy, based on interdisciplinary research evidence. My approach is conceptualised as a: Healthy Linguistic Diet approach and every policy maker and leader in education, health and economy willing to take it on board could confidently expect to see short term and long term benefits in terms of educational attainment, cognitive enhancement, well-being throughout different life stages, health benefits especially in advanced age and a boost to the economy.

According to its report on the State of the Nation, (Tinsley 2013), the deficiency of language skills was identified by the British Academy as being so severe amongst the available and newcoming workforce that some large companies had started deleting language requirements from their adverts and staff profile requirements, having to focus their business strategies on English speaking countries only. The Report terms this phenomenon the 'creation of a vicious circle of monolingualism'. (Tinsley 2013: 11)

Without any doubt this vicious circle of monolingualism rests on the dominance of the English language unrivalled by any other language in our history: ' no other language has been spoken by so many people in so many places ... one in four of the human race is competent in English'. (Crystal 2002: 10). Current British Council estimates also confirm this figure resulting in a false feeling of 'English is enough', reflected in the decline of languages learning and skills. (British Council 2014) Therefore, I would like to advocate that current attempts to promote language learning in the UK need to use new and different arguments than the ones used in other countries and contexts, such as globalisation, mobility and employability. In this chapter I will outline cognitive benefits linked to language learning within my Healthy Linguistic Diet approach, which are 
entirely intrinsic and therefore liberated from the burden of having to prove useful in the context of English language dominance.

\section{Key Concepts: Bilingualism, Multilingualism, Plurilingualism}

The definition of bilingualism encompasses huge variations across different contexts. The common feature of all definitions available in theory and in practice lies in the recognition that bilingualism at the individual and societal level refers to the existence of two languages - meaning the recognition that a number of individuals and communities use two languages in their everyday lives. In some cases, like the definition that is used in mainstream schools in England, the 'existence' of two languages is defined as 'exposure to two languages; living in two languages'. (Eversley et al. 2010). This is a very inclusive definition, which avoids complex and in some cases hard to measure aspects of language use: competency, proficiency, fluency and literacy. The reasons why it is essential for schools to have a broad, inclusive definition of bilingualism are explored below.

The criterion of 'living in two languages' allows for the inclusion of a variety of profiles of bilingual pupils. These different profiles can be divided into three main categories, discussed here in the context of England and its mainstream education.

First are bilinguals born and educated in England. They are children from wellestablished immigrant communities, mainly originating from the Commonwealth countries: India, Bangladesh and Pakistan. Second are recent immigrant bilinguals. They come from many different European, Asian, African and South American countries. They are mainly new to English and have various degrees of literacy in their first language. The third group consists of settled immigrant bilinguals. These children were not born here, but have been immersed in an English speaking environment for different lengths of time. They are at different stages of developing bilingualism depending on their backgrounds, support and abilities. They differ from bilinguals born here mainly by having had some of their formal education in a language other than English. Therefore, in many cases, they have higher levels of literacy and background knowledge in that other language. (Mehmedbegovic 2011)

Having a definition that enables teachers and practitioners in mainstream education to identify all these different cases as types of bilingualism is essential in order to: collect data that accurately reflect the full range of societal bilingualism; that recognise experiences and language practices which children engage with outside school; that identify a variety of needs in terms of language development and language support that these children may have; and that can inform the allocation of funds available for language development, either in English or in their home language.

The term multilingualism is used widely by practitioners and policy makers within the education system in England, especially London. In the context of schools, practitioners and policy makers in England refer to 'multilingual schools', 'multilingual classrooms' and 'multilingual communities of learners'. In reality this is in recognition of the fact that some or many students in these schools have a language other than English as a part of their 
lives, mainly outside their mainstream school. In educational literature, multilingual schools and classrooms are defined as having the curriculum taught in different languages - for example in international schools.

On the other hand, the Council of Europe's policies promote a vision and a discourse of plurilingualism, as explored below. Often the question is asked: what is the difference between multilingualism and plurilingualism? The main distinction for the Council of Europe is that a multilingual approach is about having many different languages coexist alongside each other, but separately, within individuals or society with the ultimate aim of achieving the idealised competency of the native speaker in each language. (Council of Europe 2001: 4) A plurilingual approach, on the contrary, places emphasis on the development of effective communication skills which draw on all of our linguistic and cultural experiences in an interactive way. This is promoted as a life-long activity, a process of learning the language of home, society, other peoples; developing communicative competencies throughout our lifetime; and in different situations flexibly calling upon different parts of this competence in order to achieve effective communication. Plurilingualism recognises an all-encompassing communication competence that is made up of different languages that one person has been exposed to and acknowledges the partial nature of the knowledge anyone can have of one language, be it their mother tongue or not. Therefore plurilingualism removes the ideal of the native speaker as the ultimate achievement and replaces it with the aim of an effective pluralistic communicator who draws on his/her varied repertoire of linguistic and cultural knowledge in a flexible, creative and individual way. (Council of Europe 2001: 4, 5, 169) The emphasis in this process is on attitude formation and language and cultural awareness as essential to one's understanding of social and physical environments and ability to function effectively in local, national and international environments. (Tosi and Leung 1999: 17) Plurilingualism provides a true qualitative leap in terms of understanding, conceptualising and developing models of practice, which include home language support. My Healthy Linguistic Diet proposal is underpinned by the understanding of language learning and language competencies as defined by the plurilingual approach.

\section{Cognitive advantages of bilingualism and language learning}

Clinical research studies carried out in the second part of the $20^{\text {th }}$ century involving bilinguals (those who use two languages) and monolinguals (those who use one language) provide a significant body of evidence which covers differences in a wide range of variables:

- visual presentation and processing,

- audio processing,

- brain activity and engagement. 
Jim Cummins lists 160 studies focused on bilinguals in education from different countries and contexts: all of which provide evidence that bilingual children perform better than monolingual children across the curriculum. (Cummins 2000)

Studies conducted with early years and school age children have found that bilingual pre-school children demonstrate better focus on tasks while ignoring distractions than their monolingual peers. A similar enhanced ability to concentrate has been found in bilingual adults, particularly those who became fluent in two languages at an early age. Managing two languages helps the brain sharpen and retain its ability to focus while ignoring irrelevant information. (Bialystok 1999)

More recent studies with adults have provided insights into physical changes, which happen in the brain when two languages are used, demonstrated as the enhancement of brain matter. Bilingual adults have denser grey matter (brain tissue packed with information processing nerve cells and fibres), especially in the brain's left hemisphere where most language and communication skills are controlled. The effect is strongest in people who acquired a second language before the age of five and in those who are most proficient at their second language. This finding suggests that being bilingual from an early age significantly alters the brain's structure, and that the proficiency and intensity of use result in the same benefits. (Kovelman, Baker, and Petitto 2008) This type of evidence is crucial in raising awareness that language learning is a valuable life-long activity. It also shows that it is wrong to think that older learners do not gain cognitive benefits from it. The 'Never too late?' study provides evidence that although earlier and later language learners enjoy a different range of benefits, they all have significant advantages in comparison with people who only have one language. (Bak, VegaMendoza, and Sorace 2014)

Bilinguals also show significantly more activity in the right brain hemisphere than monolingual speakers, particularly in a frontal area identified as the source of the bilingual advantages in attention and control. This expanded neural activity is so consistent on brain scans that it has been labeled as a "neurological signature" for bilingualism. (Kovelman, Baker, and Petitto 2008)

The latest evidence is even more significant in terms of one's well-being. The most recent research studies conducted in Canada identify bilingualism as a big hope in equipping ourselves better to engage with the threat of dementia: 'Executive brain power', developed by the use of two languages, has been identified as a key factor in prolonging quality life in later life and fighting off the onset of dementia by three to five years. (Bialystok, Craik, and Luk 2012, Freedman et al. 2014).

Similarly, researchers from the University of Edinburgh examined the medical records of over 600 people in India. They found that people who spoke two languages did not show any signs of dementia for more than four years longer than those who used one language. (Mortimer et al. 2014, Freedman et al. 2014) 
Based on this evidence bilingualism is increasingly appreciated as successful brain training, contributing to a cognitive reserve which can help delay dementia. Dr Thomas Bak, the principle researcher at University of Edinburgh, states that: "These findings suggest that bilingualism might have a stronger influence on dementia that any currently available drugs. This makes the study of the relationship between bilingualism and cognition one of our highest priorities."1 What implications do these findings have on our highest priorities for bilingualism in education? And what evidence do we have that bilingualism enhances academic achievement? This is addressed next.

\section{Bilingualism and academic achievement}

The cognitive advantages of bilingualism, specifically in terms of academic achievement, are linked to the processes of being exposed to two languages and therefore having broader linguistic experiences and access to a wider range of thinking modes. Switching between the two languages has been identified as a good 'brain exercise' resulting in more flexible thinking. The comparison of two languages and using the knowledge of one language to advance the other result in enhanced higher-level linguistic skills known as metalinguistic skills. These findings confirm ideas first promoted by one of the most recognised development psychologists, Lev Vygotsky. He viewed bilingualism as key for a child to approach language in a more abstract way and in more general categories. (Vygotsky 1962: 110)

The evidence of children approaching language and other academic content in a more abstract mode is clearly outlined by two Canadian researchers, Lambert and Tucker, who observed and tested a group of six-year-olds educated mainly in their second language. In this longitudinal study the observed children demonstrated a high level of interest in comparing their two languages; approaching their second language as a code; using their first language as the basis for relating and translating both academic content and linguistic input. Therefore, the researchers were proposing that the acquisition of the second language had benefited not only the competence in their first language, but also their mastery of the academic content. (Lambert and Tucker 1972: 82)

It is also important to reflect on the fact that some studies have identified minor disadvantages of bilingualism, while there are also studies that provide both types of

evidence. For example, Ben-Zeev (Ben-Zeev 1977) reports a delay in recalling certain words, while at the same time participants in this study showed advantages in terms of more analytical tasks, for example word classification.

However, it can be said with certainty that there is a consensus amongst researchers who strongly support bilingualism as a source of cognitive advantage. The following quote from Bialystok captures what can be seen as the consensus in this area of research:

...bilingualism never confers a disadvantage on children who are otherwise equally matched to monolinguals and the benefits and potential benefits weigh in to make bilingualism a rare positive experience for children. (Bialystok 2006: 598) 
This concludes a brief overview of select relevant studies and their key findings. Next, I will outline my approach: Healthy Linguistic Diet.

\section{Educational priorities}

The research evidence presented in this paper underpins my argument that bilingualism is a source of cognitive advantage so significant at the individual and societal level that it is not only an education imperative to promote it, but a moral one too. According to the Alzheimer's Society, delaying the onset of dementia by five years would reduce deaths directly attributable to dementia by 30,000 a year. Dementia costs the UK $£ 23$ billion per year, yet the government has no plan on how to deal with dementia now or in the future. ${ }^{2}$

If bilingualism is identified currently as the most promising strategy known in terms of prolonging a dementia free life there certainly should be no delay in working on timely and necessary changes throughout the education system in order to benefit from its' advantages.

For these changes to happen it is necessary to shift the thinking throughout the education system, from policy makers to school leaders, practitioners, learners and parents. The first imperative is that all the stakeholders should be aware of what qualitative difference bilingualism can make to their cognitive functioning in general, and specifically in later life. The second imperative is that all stakeholders need to be equipped with strategies that can transform school practice and independent learning.

This shift in policy and practice needs to start with school leaders and the school workforce. By promoting the development of school policies and practices which are crucial for an extended, dementia-free life, we are at the same time offering enhanced cross-curriculum performance for bilingual children and all those eager to learn other languages. Enhanced school performance is a key aspect in this shift, which will be of interest to every school leader and teacher.

\section{New strategy: Healthy Linguistic Diet}

My concept of a Healthy Linguistic Diet is based on the principle that all languages used by school children need to be supported in order to be maintained and developed further for the purposes of cognitive benefits. These benefits are not only needed by individuals from bilingual backgrounds, they are needed by schools too as well as governments. For schools they mean better results in league tables; for governments they mean billions of savings in later life care.

The same applies to all languages used and spoken by adults and all approaches to lifelong learning.

I envisage my Healthy Linguistic Diet as a strategy which would in the first instance: provide structured spaces for children and adults to discuss 'being bilingual' with the aim 
or raising awareness of bilingualism and its benefits. The reason I start with explicit discussions about bilingualism is derived from a 'critical incident' moment I had in a London school, which led to my conceptualisation of a Healthy Linguistic Diet. While facilitating a discussion group focusing on exploring reasons for underachievement with a group of Bangladeshi boys, one participant stated: 'We underachieve because we speak two languages'. His friend replied: 'It is not true, I read in a scientific journal that bilingualism improves your brain.' (Mehmedbegovic 2011) What struck me here as a critical incident was realising that 14 year old bilingual children were not given opportunities to learn about bilingualism in terms of research evidence and the impact of bilingualism on cognitive functioning. From this example it is clear that some children internalise a deficit model of bilingualism through a lack of any other model or explicit information on what it means to be bilingual, while those who are looking to gain knowledge about bilingualism have to do their own research for literature outside of expected interests and reading for young people in secondary education.

Based on this first-hand experience from an inner London school I have been working on developing principles and strategies which can be used for an approach conceptualised as similar to thinking about a healthy diet - in this case it is a linguistic diet. Considering the big push for healthy lifestyles and healthy eating under the umbrella initiative Healthy Schools, I would like to suggest that the concept of a healthy linguistic diet should be integrated into this Healthy Schools initiative. 3 A Healthy Linguistic Diet has real potential to contribute to the aims outlined by the government: raise achievement across the curriculum, improve long term health, enhance well-being and improve inclusion. The following are suggestions for the key whole-school strategy.

\section{Providing regular and rich opportunities for engagement and use of both or several languages}

Teachers and school leaders need to find regular opportunities to provide a consistent flow of affirmative messages with the aim of eliminating misconceptions about bilingualism as a problem and bad practices based on these misconceptions. These messages should also highlight that most cognitive benefits of bilingualism apply also to those who learn another language in school/university/outside of school.

Teachers need to be provided with examples of good practice, guidance and training to develop skills essential for integrating home languages across the curriculum. This shift in practice should be led by the awareness that where home languages are a part of teaching and learning, the impact of it will be evident in improved results across the curriculum as a whole. This approach, which includes home and foreign languages, should start with early years learning and continue throughout compulsory and life-long education. The overall aim should be to support bilingual children in developing their full potential, and to encourage positive attitudes towards this specific intellectual potential that they have. At the same time, approaches used to support children in maintaining their home languages should also be utilised for all children in order to develop interest and enthusiasm for learning other/foreign languages. 
A recent EU funded project, LUCIDE (Languages in Urban Communities for Integration and Diversity in Europe), has produced a set of toolkits: guidance documents with examples for educators and other professionals in public services which can be a very useful starting point and used as ongoing support in developing good practice. These toolkits are based on research evidence and examples of good practice collected from a network of 13 European multilingual cities including London and in partnership with cities from Canada and Australia. ${ }^{4}$

\section{Providing access to and sharing relevant knowledge on the values and advantages of bilingualism}

Bilingual children and their parents need to be given clear, affirmative and consistent messages by schools and their teachers in terms of the benefits of bilingualism and home language support. Students (and parents) should be given advice on what they can do themselves in order to support their own bilingual development. These messages should include raising awareness on the cognitive advantages of bilingualism, which are applicable to all languages.

Bilingualism Matters Centres, whose mission is to provide evidence and advice to all stakeholders (parents, educators, policy makers) to make informed decisions regarding bilingual children, would make excellent partners to schools and school leaders in securing access to the latest research evidence.. 5

Providing a framework which supports life-long development of bilingual competencies

All children (monolingual and bilingual/plurilingual) and adults (monolingual and bilingual/plurilingual) in schools and other educational contexts should be encouraged to develop behaviour and habits that would support life-long development of bilingual/plurilingual competencies. These practices need to become an integral part of efforts to bring up children in the spirit of the Healthy School Initiative leading to a healthy life style.

The Council of Europe places particular importance on life-long development of plurilingual competencies: plurilingulism is defined as competencies in different languages and their varieties which individuals engage with in their lifetime. EU language policy is based on the principle that all individuals 'are entitled to develop a degree of communicative ability in a number of languages over their lifetime in accordance with their needs'.6

\section{Raising awareness among adults}

In my own experience I have found that there is very little understanding about dementia amongst professionals in public services, nor in general amongst the adult population I encounter through my work and privately. Unless somebody has a family member sinking into dementia, there is a lack of understanding that dementia is not only about forgetting names or dates, it is about irreparable loss of one's overall mental capacity. In practical terms, that means: loss of the ability to read, write, speak, eventually even walk, eat and swallow. It is a slow death of one's brain and all its' functions. Understanding it fully means accepting it as a terrifying prospect with a fast increasing probability that it may 
happen to them for a greater number of people. This is especially true for people living longer in the developed world.

Dementia is often diagnosed too late - this is due to a lack of awareness, the stigma around mental health and the medical fraternity's inability to prevent or reverse the illness. If we want to change any of this we need to work closely with medical professionals and adult educators. The approach would first of all involve raising awareness amongst these key professionals on the benefits of bilingualism in terms of extending dementia-free life by several years, as the research shows. They would then use opportunities to promote the importance of learning other languages as a life-long activity. In the same way that a GP would ask patients about physical activity and highlight that for a healthy heart one needs to walk, swim and be active in different ways, he/she would also highlight the increasing risk of dementia and promote language learning as a way to maintain a healthy brain. Indeed, parallels can easily be drawn between physical activity and keeping our heart strong and healthy on the one hand, and mental engagement and having a brain that can fight off dementia for a few years longer, on the other hand.

Also, strategies of wider engagement such as publicity and education through available media need to be used - for example in the same way healthy eating is promoted in different ways amongst different age groups. News items, documentaries, adverts, films, TV programmes, language clubs and activities - policy makers should consider all available media in order to raise awareness and motivate the adult population to engage in life-long language learning.

\section{Conclusion}

Health and social care costs for dementia patients in England are currently around $£ 8.2$ billion according to The National Audit Office. Alzheimer's Research UK has estimated that the overall cost of dementia to society as a whole is $£ 23$ billion a year. They also estimate that savings of $£ 80$ million could be made every year by improving hospital care. My question is: What savings can be made by promoting bilingualism such as through a Healthy Linguistic Diet?

Loss of a home language is often presented as a natural language shift or freedom of choice, as evidenced in my study on attitudes to bilingualism. (Mehmedbegovic 2011) Evidence shows that underprivileged communities suffer more language loss than affluent ones. Therefore, by not equipping underprivileged communities with awareness on the equal benefits of all languages we are widening the rich-poor gap in yet another way. Every effort needs to be made to ensure that children from minority groups do not drift towards language loss, in the form of loss of their home language.

Language loss is a loss for all who aim to achieve:

- Better attainment across the curriculum; 
- A better equipped workforce for a globalised world;

- Better self-esteem at an individual level;

- Longer dementia-free lives and significant cost savings for society.

Therefore the maintenance of home languages and learning of other languages should be positioned in education and life-long learning as a basis for enhancing human cognitive potential and equipping oneself for a better quality of life in later life. The equal value of cognitive benefits linked to bilingualism and language learning/use regardless of what combination of languages is in question (English-French or English-Bengali or EnglishWelsh) needs to be promoted and explicitly communicated to all stakeholders: children, parents, carers, teachers and school leaders. In my research and engagement with stakeholders in different contexts I have identified one big obstacle in utilising the existing linguistic diversity in the UK: hierarchy of languages. By hierarchy of languages I mean the outcome of processes and perceptions which result in a small number of select languages being considered high status, desirable to learn and 'have' such as French and Spanish, and a much larger number of languages which are not seen as an asset and have a very low status value, resulting in language loss at the individual level (Punjabi is one example I identified as such in my research) and language death at the societal level (Cornish is one of the languages which, in recent years, was identified as endangered and then dead, although there are attempts to revive it) .

The dichotomy of high and low status languages, underpinned by historic reasons such colonialism and/or economic dominance, prevent minority groups from being aware of the value of their languages. Hence my plea that a sharp U-turn needs to be made in terms of presenting and promoting the cognitive benefit rationale for developing bilingual skills. The rationale embedded in the cognitive benefits of bilingualism overcomes the issue of language hierarchy and this is the winning card that I suggest should be used to promote language learning in the UK. The cognitive benefits rationale also overcomes the 'English is enough' fallacy discussed at the beginning of this article.

This Healthy Linguistic Diet approach promotes the equality of all languages in terms of their impact on our well-being and cognitive functioning. It makes every individual aware that no matter what languages they have the opportunity to learn and be exposed to: French, German, Bengali, Polish or any other, they are making an equally valuable effort and investment in their own long-term well-being and consequently also the long-term well-being of the wider society as a whole. 


\section{References}

All-Party Parliamentary Group on Modern Languages. 2014. "Manifesto for Languages." In. https://www.britishcouncil.org/sites/default/files/manifesto for languages.pdf.

Bak, Thomas H., Mariana Vega-Mendoza, and Antonella Sorace. 2014. "Never too late?: An advantage on tests of auditory attention extends to late bilinguals." In Frontiers in Psychology. http://journal.frontiersin.org/article/10.3389/fpsyg.2014.00485/full (accessed 26 May).

Ben-Zeev, Sandra. 1977. "The Influence of Bilingualism on Cognitive Strategy and Cognitive Development." Child Development 48 (3):1009-1018.

Bialystok, Ellen. 1999. "Cognitive complexity and attentional control in the bilingual mind." Child Development 70:636-644.

Bialystok, Ellen. 2006. "The Impact of Bilingualism on Language and Literacy Development." In The Handbook of Bilingualism, edited by TK Bhatia and WC Ritchie. Oxford: Blackwell.

Bialystok, Ellen, Fergus I. M. Craik, and Gigi Luk. 2012. "Bilingualism: Consequences for mind and brain." Trends in Cognitive Sciences 16:240-250

British Council. 2014. "Languages for the Future. Which languages the UK needs most and why." In. https://www.britishcouncil.org/sites/default/files/languages-for-the-future-report-v3.pdf.

Council of Europe. 2001. Common European Framework of Reference for Languages: Learning, Teaching, Assessment. Cambridge: Cambridge University Press.

Crystal, David. 2002. Language Death Cambridge: Cambridge University Press.

Cummins, Jim. 2000. Language, Power and Pedagogy. Clevedon: Multilingual Matters.

Eversley, John, Dina Mehmedbegovic, Antony Sanderson, Teresa Tinsley, Michelle Von Ahn, and Richard D.. Wiggins, eds. 2010. Language Capital: Mapping the Languages of London's school children. London: CILT.

Freedman, Morris, Suvarna Alladi, Howard Chertkow, Ellen Bialystok, Fergus I. M. Craik, Natalie A. Phillips, Vasanta Duggirala, Surampudi Bapi Raju, and Thomas H. Bak. 2014. "Delaying Onset of Dementia: Are Two Languages Enough?" Behavioural Neurology 2014:Article ID 808137, 8 pages.

Kovelman, loulia, Stephanie A. Baker, and Laura-Ann Petitto. 2008. "Bilingual and monolingual brains compared using $\mathrm{fMRI}$ : Is there a neurological signature of bilingualism?" Journal of Cognitive Neuroscience 20 (1):1-17.

Lambert, Wallace E, and G. Richard Tucker. 1972. Bilingual Education of Children: The St. Lambert Experiment. Rowley, Mass.: Newbury House.

Mehmedbegovic, Dina. 2011. A study in attitudes to minority languages in England and Wales. Saarbrucken, German: Lambert Academic Publishing.

Mortimer, J, AS Alladi, TH Bak, TS Russ, M Shailaja, and V Duggirala. 2014. "Bilingualism delays age at onset of dementia, independent of education and immigration status." Neurology 81 (22):1936-44. 
Tinsley, Teresa. 2013. "Languages: The State of the Nation." In. London: British Academy. http://www.britac.ac.uk/publications/languages-state-nation.

Tosi, Arturo, and Constant Leung, eds. 1999. Rethinking Language Education: From a Monolingual to a Multilingual Perspective. London: CILT.

Vygotsky, Lev. 1962. Thought and Language. Cambridge: MIT Press,.

\footnotetext{
${ }^{1}$ See the website of Bilingual Matters: http://www.bilingualism-matters.ppls.ed.ac.uk ${ }^{2}$ See the website of the Alzheimer's Society: http://www.alzheimers.org.uk/site/scripts/press_article.php?pressReleaselD=90

${ }^{3}$ Information on this is available at: http://dera.ioe.ac.uk/6798/1/Introduction.pdf.

${ }^{4}$ These can be accessed at: http://www.urbanlanguages.eu/

${ }^{5}$ In the UK there two Bilingualism Matters centres: in Edinburgh and Reading. Information about their mission, activities and possibilities for partnerships can be accessed on the website: http://www.bilingualism-matters.ppls.ed.ac.uk/branches/branch-network/ ${ }^{6}$ Information about Council of Europe work in this area can be found at: http://www.coe.int/t/dg4/linguistic/Division_EN.asp
} 